\title{
Tannin extracted from Sumac inhibits vascular smooth muscle cell migration
}

\author{
Hanieh Zargham, Ramin Zargham*
}

\begin{abstract}
Background - Vascular smooth muscle cell (VSMC) migration is integral in the pathogenesis of atherosclerosis. Sumac (Rhus coriaria) berries are believed to have atheroprotective effects. Therefore, Sumac, which is a rich source of tannin antioxidants, was tested for its capacity to inhibit VSMC migratory activity. Materials \& Methods - Tannin was extracted and purified from ground Sumac. Cultured rat carotid VSMCs were treated with different concentrations of tannin. After 10 days of tannin treatment, VSMC migratory activity in response to platelet-derived growth factor-BB was measured by transmembrane migration assay. An equal number of VSMCs was loaded on top of the inserts and at the bottom of the wells. After fixation and staining, cells migrating through the inserts and cells seeded at the bottom of the wells were counted. Results - A significant reduction (62\%) of VSMC migration was evident in tannin-treated cells. To rule out any possible toxicity and cell death, cells at the bottom of the wells were also counted. No difference between the tannin-treated group and the controls was observed in the number of cells seeded at the bottom of the wells.Conclusion - Our data suggest that tannin extracted from Sumac possesses potent antimigratory activity. Sumac may have potential for the prevention or treatment of atherosclerosis and its clinical manifestations. Further experiments, especially in vivo, are required to examine the atheroprotective effect of Sumac.
\end{abstract}

KEYWORDS: vascular smooth muscle cell, migration, atherosclerosis, Sumac, tannin

\section{INTRODUCTION}

Atherosclerotic vascular disease is swiftly becoming the leading cause of morbidity and mortality worldwide. In the United States alone, approximately 13.2 million individuals suffer from documented coronary artery disease (1). Atherosclerosis of the coronary arteries evokes the most serious clinical manifestations of this disease, including unstable angina, acute myocardial infarction, and sudden death (2). Atherosclerosis is characterized by endothelial dysfunction, vascular inflammation, and the buildup of lipids, cholesterol, calcium, and cellular debris within the intima of the vessel walls (3). The release of cytokines and growth factors from activated platelets and macrophages at the

*To whom correspondence should be addressed:

Ramin Zargham MD, PhD

McGill University, Experimental Medicine department, Montreal, Canada, H2W1R7.

Email: ramin.zargham@mail.mcgill.ca lesion site culminates in the heightened migratory activity of vascular smooth muscle cells (VSMCs). It is thought that VSMCs derived from the tunica media migrate towards the atherosclerotic lesion, proliferate and synthesize extracellular matrix, thereby contributing to atheroma growth. Platelet-derived growth factor (PDGF), secreted by activated platelets and lesion macrophages, is the most potent stimulus of VSMC attraction to the intima. It induces rapid downregulation of smooth muscle-selective markers in cultured VSMCs and stimulates VSMC migration in arterial injury models $(4,5)$. Any strategy to inhibit VSMC migration would benefit the treatment of atherosclerosis. Although many studies have focused on the blockade of VSMC migration, no effective therapy has yet been established.

Recently, natural products and foods such as red wine polyphenols have been shown to inhibit VSMC migration (6). In Persian traditional medicine, Sumac 
(Rhus coriaria) is believed to have atheroprotective effects and is consumed in some Persian dishes. This spice comes from the berries of a wild bush that grows in all Mediterranean areas. Previous studies have suggested that methanolic extracts of Rhus coriaria L. fruits may be a source of natural antioxidants $(7,8)$.

Sumac is a rich source of hydrolysable tannins (9). Tannins have been shown in vitro and in vivo to exhibit anticarcinogenic properties, such as the induction of cell cycle arrest and apoptosis as well as the inhibition of tumor formation and growth in animals (10). Therefore, we tested tannin extracted from Sumac for its capacity to suppress VSMC migratory activity.

The present study presents a methodological approach to determining whether tannin extracted from Sumac inhibits VSMC migration without causing cell death.

\section{MATERIALS AND METHODS \\ Tannin extraction from Sumac}

Two grams of dry Sumac (Aliments Akhavan, Montreal, Quebec) were ground using a mortar and pestle. To dissolve tannin in solvent, the ground Sumac was transferred to $50 \mathrm{~mL}$ Falcon tubes and $20 \mathrm{~mL}$ of acetone and water (7:3 ratio) was added. The collected tannin extracts were sonicated for $30 \mathrm{~min}$ at $4 \mathrm{oC}$ to break down additional materials associated with tannin. To pellet the additives and salts, the sonicated tannin extracts were centrifuged for $10 \mathrm{~min}$ at 2,500 rpm. The supernatants were removed from the pellets and tannin was separated from acetone in a Rota-evaporator. The extracted tannin was filtered and stored at $4 \mathrm{oC}$ until used. Extraction was repeated 2 more times. The $\mathrm{pH}$ of the extracted tannin was adjusted to 7.2 by titrating the tannin extract with $1 \mathrm{M} \mathrm{NaOH}$.

\section{Isolation of rat carotid VSMCs and treatment with tannin}

The carotid arteries of male Sprague-Dawley rats (Charles River Laboratories, St. Constant, Quebec) were excised to isolate VSMCs, as described previously (11). Animal housing and experimentation in accordance with Canadian Council on Animal Care and $\mathrm{NIH}$ guidelines were approved by the local animal care committee.

The optimal tannin concentration was defined in terms of VSMC survival. VSMCs were seeded in $10 \mathrm{~cm}$ culture dishes, treated with different tannin concentrations contained in Dulbecco's Modified Eagle Medium (DMEM) for 10 days. The different tannin concentrations were $5 \%, 1 \%, 0.5 \%$, and $0.1 \% \mathrm{ml}$ of tannin extract per ml of DMEM. Cultured VSMCs in tannin-free media were used as control.

\section{Transmembrane migration assay}

Cell migration was measured in a Transwell migration apparatus (Becton Dickinson Labware, Franklin Lakes, NJ) with $8-\mu \mathrm{m}$ pore-size, fibronectin-coated membranes. From a concentration of 100,000 per $\mathrm{ml}$ of rat carotid VSMCs, $200 \mu \mathrm{L}$ were loaded in the upper chamber whereas $630 \mu \mathrm{L}$ of cells were loaded in the lower chamber. The cultures were incubated for $2 \mathrm{~h}$ at $37^{\circ} \mathrm{C}$. PDGF-BB $(20 \mathrm{ng} / \mathrm{mL}$ ) (purchased from Sigma, Montreal, Quebec) was added to the bottom wells. After $14 \mathrm{~h}$, the cells remaining on the upper membrane (that had not migrated through the filter) were removed with a cotton swab. The membranes were subsequently washed with phosphate buffered saline (PBS) and cells adhered under the membrane were fixed with $2 \%$ glutaraldehyde and stained with crystal violet as previously described [12]. The data are reported as the number of VSMCs in 4 random fields/filter. Each experiment was done in triplicate.

\section{Statistical analysis}

The results are expressed as means \pm S.D. The difference between groups was evaluated by 1-way ANOVA and student's t-test by 2 independent investigators in a blinded fashion. Statistical significance was accepted at $\mathrm{P}<0.05$.

\section{RESULTS}

Tannin (extracted from Sumac)-treated VSMCs exhibit lower migratory activity in response to PDGF-BB

VSMCs were treated with different concentrations of tannin for 10 days. Tannin extracts were diluted in DMEM to obtain different tannin concentrations that were added to VSMC cultures to assess survival. These concentrations $(5 \%, 1 \%, 0.5 \%$, and $0.1 \%)$ were randomly chosen. Both $5 \%$ and $1 \%$ tannin extracts evoked considerable cell loss (the majority of cells were shrunk and fragmented with many dead cells floating) and were considered to be toxic. The optimal dilutions, $0.5 \%$ and $0.1 \%$ tannin extracts, did not elicit significant cell loss compared to cells without tannin treatment. (The cells were well stretched and appeared healthy and attached to the dish)

After 10 days of tannin treatment, VSMCs were loaded at the top of Transwell transmembrane inserts and at the bottom of the wells. PDGF-BB $(20 \mathrm{ng} / \mathrm{mL})$ was added to the bottom of the wells to stimulate VSMC migration through pores of the inserts. Migrated cells were counted under light microscope $14 \mathrm{~h}$ after addition of PDGF-BB. The $0.1 \%$ tannin extract group did not yield any difference. The average migration (based on light microscopy) was 55 cells in the absence of tannin (with standard deviation of 3.4), 54 cells in the 


\section{Figure 1.}

A.

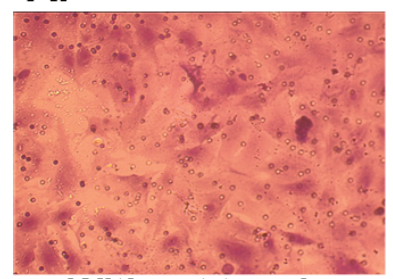

Without tannin

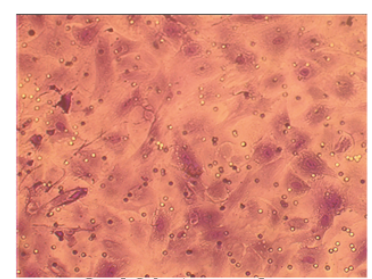

$0.1 \%$ tannin

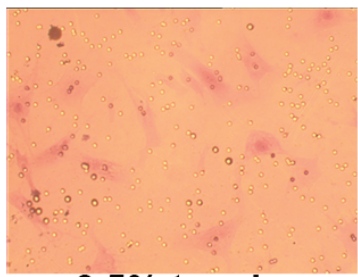

$0.5 \%$ tannin

B.

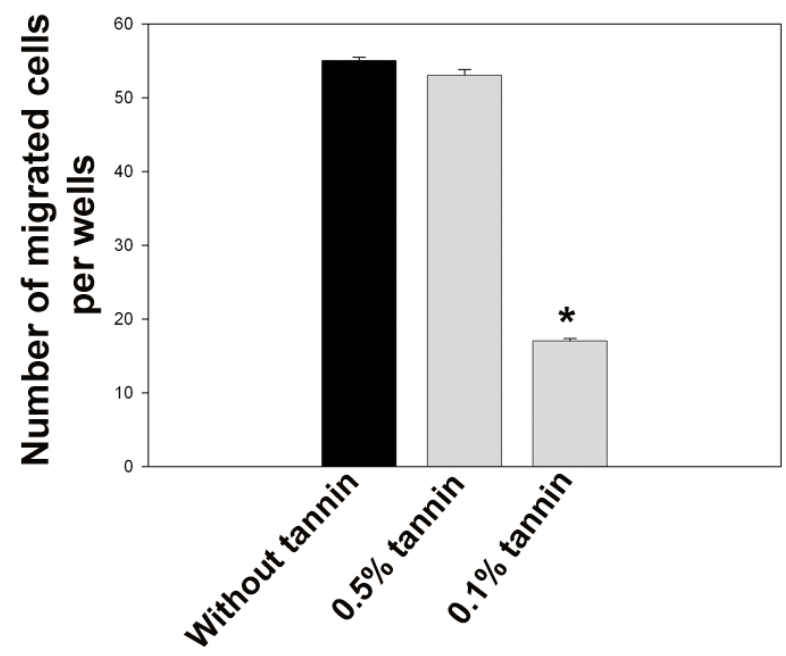

Figure 1: Migration of rat carotid VSMCs after $10 \mathrm{~d}$ of tannin treatment. Migration was stimulated by the addition of PDGF-BB (20 ng/mL) to the lower chamber. VSMCs were allowed to migrate for $14 \mathrm{~h}$. Representative images of crystal violet-stained cells that migrated to the lower surface of the membrane are shown for tannin-treated $(0.5 \%$ and $0.1 \%)$ vs untreated VSMCs (A). Cell counts on the lower face of the membrane reveal reduced motility of VSMCs treated with $0.1 \%$ tannin extract (B). The data are expressed as means $+\mathrm{SD}$ of each experiment performed in triplicate. ${ }^{*} \mathrm{P}<0.005$ vs. untreated cells. $\mathrm{n}=4$ wells per treatment group (4 fields/well).

presence of $0.1 \%$ tannin extract (with standard deviation of 4.5 ), and 17 in the presence of $0.5 \%$ tannin extract (with standard deviation of 1.9). Repeated experiments showed a similar pattern. These data are shown in Figure 1. The results demonstrate that the addition of optimal dose of tannin extract inhibited VSMC migration by $62 \%$.

\section{No difference in cell viability between tannin- treated and control cells}

It was possible that the reduced number of migrated cells was due to toxicity of the product. To rule out any possible toxicity and cell death, cells at the bottom of the wells were also counted. No difference between the tannin-treated and untreated groups was found in the number of cells seeded at the bottom of the wells, confirming that the observed reduction in the number of migrated cells was not due to cell loss.

\section{DISCUSSION}

Numerous studies have reported that VSMC accumulation plays a major role in the pathogenesis of occlusive vascular diseases $(12,13)$. The results of recent studies suggest that antioxidants can cure or prevent atherosclerosis (14,15). Tannin and its derivatives are strong antioxidants and it is known that antioxidants can inhibit mechanisms leading to VSMC migration $(16,17)$.

In the present work, we investigated Sumac, a rich source of tannin (9), and its ability to inhibit VSMC migration. Pure tannin extracted from Sumac by analytical chemistry reduced VSMC migration at an optimal dosage. We found that at an optimal dose, pure tannin extracted from Sumac reduced VSMC migration by $62 \%$.

Red wine is also a source of tannin. It has been reported that the consumption of red wine, which owes its antioxidant properties to tannin, imparts benefits in 
the prevention of early atherosclerosis (18). Several epidemiological studies have shown a negative association between moderate wine consumption with the risk of cardiovascular events (19). A recent study has demonstrated that red wine polyphenols inhibit VSMC migration (6). However, there is a difference between the tannins present in Sumac and those in wine. Tannins are divided into 2 major classes: hydrolysable and condensed. Condensed tannins are not susceptible to cleavage by hydrolysis, are larger than hydrolysable tannins and their large size precludes absorption, suggesting that they are unlikely to have many health effects (20). In contrast to the condensed tannin from red wine (20), tannin extracted from Sumac is hydrolysable (21) and therefore may be easier to digest and absorb. Also, while high alcohol consumption results in high blood pressure (hypertension) and has a positive correlation with esophageal cancer (22), no negative side effects have been reported for Sumac. Other studies of tannin derivatives, including the one by Ignarro et al. (23), have shown that pomegranate juice can increase nitric oxide, thereby reducing the process of atherosclerosis. Interestingly, tannin from pomegranate juice is also hydrolysable. These results imply that Sumac, through it hydrolysable tannins, presents a preventative modality for the development of atherosclerosis. Further investigation is needed, to establish the in vivo significance of our in vitro findings.

One limitation of this study is the use of rat VSMCs instead of human VSMCs. Moreover, it would have been worthwhile to investigate and compare the effect of other tannin sources including red wine and pomegranate juice.

In summary, this is the first report demonstrating that tannin extract from Sumac has an inhibitory role on the migration of VSMC and thus suggests an atheroprotective role for this chemical. However, in vivo investigations are warranted to examine Sumacderived tannin compared to the tannin derived from other products.

\section{ACKNOWLEDGMENTS}

We thank Drs. Gaetan Thibault and Yvan Guindon for providing the lab facilities and materials and Tao Trinh for the technical assistance.

\section{REFERENCES}

(1) Thom T, Ha N, Rea W. Heart Disease and Stroke Statistics 2006 Update. A Report from the American Heart Association Statistics Committee and Stroke Statistics Subcommittee Source. 2006. American Heart Association Web site.

(2) Kher N, Marsh JD. Pathobiology of atherosclerosis a brief review. Semin Thromb Hemost 30: 665-72; 2004.

(3) Shah PK. Pathophysiology of plaque rupture and the concept of plaque stabilization. Cardiol Clin 21: 303-14; 2003.
(4) Axel DI, Riessen R, Athanasiadis A, Runge H, Koveker G, Karsch KR. Growth factor expression of human arterial smooth muscle cells and endothelial cells in a transfilter coculture system. J Mol Cell Cardiol 29: 2967-78; 1997.

(5) Jawien A, Bowen-Pope DF, Lindner V, Schwartz SM, Clowes AW. Platelet-derived growth factor promotes smooth muscle migration and intimal thickening in a rat model of balloon angioplasty. J Clin Invest 89: 507-11; 1992.

(6) Iijima K, Yoshizumi M, Hashimoto $M$, et al. Red wine polyphenols inhibit vascular smooth muscle cell migration through two distinct signaling pathways. Circulation 105: 2404$10 ; 2002$.

(7) Candan F, Sökmen A. Effects of Rhus coriaria L (Anacardiaceae) on lipid peroxidation and free radical scavenging activity. Phytother Res 18: 84-6; 2004.

(8) Ozcan M. Antioxidant activities of rosemary, sage, and sumac extracts and their combinations on stability of natural peanut oil. J Med Food 6: 267-70; 2003.

(9) Kosar M, Bozan B, Temelli F, Baser KHC. Antioxidant activity and phenolic composition of sumac (Rhus coriaria L.) extracts. Food Chem 103: 952-9; 2006.

(10) Perchellet JP, Gali HU, Perchellet EM, Klish DS, Armbrust AD. Antitumor-promoting activities of tannic acid, ellagic acid, and several gallic acid derivatives in mouse skin. Basic Life Sci 59: 783-801; 1992.

(11) Zargham R, Thibault G. Alpha8beta1 integrin expression in the rat carotid artery: involvement in smooth muscle cell migration and neointima formation. Cardiovasc Res 65: 813-22; 2005.

(12) Rudijanto A. The role of vascular smooth muscle cells on the pathogenesis of atherosclerosis. Acta Med Indones 39: 86-93; 2007.

(13) Doran AC, Meller N, McNamara CA. Role of smooth muscle cells in the initiation and early progression of atherosclerosis. Arterioscler Thromb Vasc Biol 28: 812-9; 2008.

(14) Ma A, Qi S, Chen H. Antioxidant therapy for prevention of inflammation, ischemic reperfusion injuries and allograft rejection. Cardiovasc Hematol Agents Med Chem 6: 20-43; 2008

(15) Siekmeier R, Steffen C, März W. Role of oxidants and antioxidants in atherosclerosis: results of in vitro and in vivo investigations. J Cardiovasc Pharmacol Ther 12: 265-82; 2007.

(16) Harimaya K, Tanaka K, Matsumoto Y, Sato H, Matsuda S, Iwamoto Y. Antioxidants inhibit TNFalpha-induced motility and invasion of human osteosarcoma cells: possible involvement of NFkappaB activation. Clin Exp Metastasis 18: 121-9; 2000.

(17) Yasunari K, Kohno M, Kano H, Yokokawa K, Minami M, Yoshikawa J. Antioxidants improve impaired insulin-mediated glucose uptake and prevent migration and proliferation of cultured rabbit coronary smooth muscle cells induced by high glucose. Circulation 99: 1370-8; 1999.

(18) Auger C, Rouanet JM, Vanderlinde R, Bornet A, Décordé K, Lequeux N, Cristol JP, Teissedre PL. Polyphenols-enriched Chardonnay white wine and sparkling Pinot Noir red wine identically prevent early atherosclerosis in hamsters. J Agric Food Chem 53: 9823-9; 2005.

(19) Rotondo S, Di Castelnuovo A, de Gaetano G. The relationship between wine consumption and cardiovascular risk: from epidemiological evidence to biological plausibility. Ital Heart J 2:1-8; 2001.

(20) Waterhouse AL. Wine phenolics. Ann N Y Acad Sci 957: 21-36; 2002.

(21) El-Sissi HI, Ishak MS, El-Wahid MS, el-Ansari MA. The gallotannins of Rhus coriaria and Mangifera indica. Planta Med 19: 342-51; 1971.

(22) Fan Y, Yuan JM, Wang R, Gao YT, Yu MC. Alcohol, tobacco, and diet in relation to esophageal cancer: the shanghai cohort 
study. Nutr Cancer 60: 354-63; 2008.

(23) Ignarro LJ, Byrns RE, Sumi D, de Nigris F, Napoli C.

Pomegranate juice protects nitric oxide against oxidative destruction and enhances the biological actions of nitric oxide.

Nitric Oxide 15: 93-102; 2006.

Ramin Zargham, MD, $\mathrm{PhD}$, McGill alumnus, is currently doing postdoctoral studies in the University of California,San Diego. He received his MD from Shahid Beheshti University in Tehran, Iran. He received his $\mathrm{PhD}$ from McGill University, division of Experimental Medicine.

Hanieh Zargham, is a senior high school student of Sacred Heart School of Montreal. 